\title{
ATUAÇÃO GOVERNAMENTAL, CRESCIMENTO ECONÔMICO E PROTEÇÃO SOCIAL: ANÁLISE DO ESTADO DO CEARÁ (2000 - 2015)
}

\section{GOVERNMENT ACTION, ECONOMIC GROWTH AND SOCIAL PROTECTION: ANALYSIS OF CEARÁ STATE (2000 - 2015)}

\author{
Márcio Kleber Morais Pessoa ${ }^{1}$ \\ João Bosco Feitosa dos Santos ${ }^{2}$
}

\section{Resumo}

Este trabalho tem por objetivo compreender o impacto da atuação governamental do estado do Ceará em relação às políticas de fomento à economia, principalmente a prática da Renúncia de receita, sobre a proteção social dos cidadãos. Para tanto, será analisada a aplicação de recursos em políticas de saúde e de educação. Os objetivos específicos são: (1) mensurar se os objetivos do Governo do Estado acerca da Renúncia de Receita e do desenvolvimento industrial foram alcançados; (2) refletir sobre a evolução dos ganhos de capital e dos ganhos de renda no estado do Ceará; (3) analisar a execução orçamentária das secretarias de educação e de saúde do governo do Estado do Ceará no período de 2006 a 2015; e (4) traçar aproximações e distanciamentos entre o conceito de "expulsões", de Saskia Sassen, e o caso estudado. O procedimento metodológico utilizado foi predominantemente um estudo bibliográfico e documental. Alguns resultados são: apesar de os objetivos do governo terem sido alcançados com as políticas de fomento à economia, os índices apontam para relativa piora na proteção social da população cearense. A realidade estudada se aproxima genericamente do conceito de "expulsões".

Palavras chave: Renúncia de receita. Atuação governamental. Proteção social.

\begin{abstract}
The objective of this work is to understand the impact of the state of Ceará 's governmental action in relation to the policies of promotion to the economy, mainly the practice of Revenue Waiver, on the social protection of citizens. Therefore, the application of resources in health and education policies will be

\footnotetext{
${ }^{1}$ Graduado em Ciências Sociais e mestre em Sociologia pela Universidade Federal do Ceará, doutorando em Sociologia pela Universidade Estadual do Ceará. É professor de Sociologia no ensino médio na rede estadual do Ceará.

${ }^{2}$ Economista, Doutor em Sociologia, professor da Universidade Estadual do Ceará no Programa de Pós-graduação em Políticas Públicas.
} 
analyzed. The specific objectives are: (1) to measure whether the State Government's objectives regarding Revenue Waiver and industrial development have been achieved; (2) to reflect on the evolution of capital gains and income gains in the state of Ceará; (3) to analyze the budgetary execution of the education and health departments of the government of the State of Ceara in the period 2010-2015; and (4) to draw approximations and distances between the concept of "expulsions", by Saskia Sassen, and the case studied. The methodological procedure used was predominantly a bibliographical and documentary study. Some results are: although the government's objectives were achieved with policies to promote the economy, the indexes point to a relative worsening in the social protection of the population of Ceará. The studied reality generally comes close to the concept of "expulsions".

Keywords: Revenue Waiver. Government action. Social protection.

\section{Introdução}

Este trabalho tem por objetivo compreender o impacto da atuação governamental do estado do Ceará em relação às políticas de fomento à economia, principalmente a prática da Renúncia de receita, sobre a proteção social dos cidadãos. Isto é, as políticas econômicas implementadas pelo governo estadual estão impactando de que forma os direitos sociais? Para tanto, será analisada a aplicação de recursos em políticas sociais, prioritariamente relacionados à educação e à saúde, e outros fatores que podem implicar em (des)igualdade social e, consequentemente, em (des)concentração de riqueza, tais como: quantidade de empregos, renda mensal média, inflação etc. que impactam na população cearense.

O período analisado se compreende entre 2000 e 2015 (ano de aprovação da Lei Orçamentária Anual [LOA] 2016). Esse período foi escolhido por compreender o início da política de reduções e isenções fiscais ancoradas na Lei de Responsabilidade Fiscal (LRF) no estado selecionado até o ano em que há dados disponíveis em quantidade satisfatória para as análises.

Os objetivos específicos são: (1) mensurar em que medida os objetivos do Governo do Estado acerca da Renúncia de Receita e do desenvolvimento industrial foram alcançados; (2) refletir sobre a evolução dos ganhos de capital e dos ganhos de renda no estado do Ceará entre 2001 e 2015; (3) analisar a execução orçamentária das secretarias de educação e de saúde do governo do Estado do Ceará no período compreendido entre 2006 e 2015; e (4) traçar aproximações e distanciamentos entre o conceito de "expulsões" (SASSEN, 2016) com o caso cearense aqui analisado.

O procedimento metodológico utilizado para efetivar a investigação foi predominantemente um estudo bibliográfico e documental (CELLARD, 2014). Destacam-se as Leis Orçamentárias Anuais, Execuções Orçamentárias, Anuários Estatísticos do Ceará, publicações 
do IBGE, além de outras legislações pertinentes para o entendimento do assunto. Além disso, foi realizada revisão de literatura sobre os temas: neodesenvolvimentismo, extrafiscalidade, desigualdades sociais, que foi essencial para o diálogo com autores, orientando a argumentação acerca do caso investigado. A análise proposta visa ao exame do conteúdo e do contexto no qual os documentos foram publicados, o que indicará relações com o momento histórico, possibilitando, por exemplo, o entendimento da conjuntura econômica a qual o estado do Ceará esteve envolvido no período estudado. (Ibidem)

\section{Contexto e conjuntura}

O Imposto sobre Operações relativas à Circulação de Mercadorias e sobre Prestações de Serviços de Transporte Interestadual e Intermunicipal e de Comunicação (ICMS) é o principal arrecadador de receitas das Unidades da Federação. No Ceará, em 1997, o Decreto No 24.569 regulamentou o ICMS em suas divisas. O documento citado possui seções específicas para "isenções" e "reduções". Assim, a partir do ano 2000, amparados pela Lei de Responsabilidade Fiscal $^{3}$, governantes cearenses vêm publicando vários outros decretos a fim de reduzir impostos de mercadorias ou serviços, ou mesmo isentá-los de taxação, implementando então a política de extrafiscalidade, isto é, utilizando as isenções e as reduções de impostos com o objetivo de regular a economia e influenciar nas tomadas de decisões dos agentes econômicos ${ }^{4}$.

Isso significa que o imposto ganha uma "função extrafiscal”, ou seja, seu objetivo deixa de ser simplesmente arrecadar, função fiscal, passando a intervir na - regular a, fomentar a, induzir a, etc. - economia. (FOLLONI, 2014; LUKIC, 2015) Dessa forma, a ideologia do Estado Liberal, que enxerga o Estado como mero expectador de uma economia autorregulada, é superada por um modelo intervencionista. (SCHOUERI, 2005 apud LUKIC, 2015)

O caso mais visível de extrafiscalidade ao conjunto da sociedade brasileira talvez tenha sido a redução do Imposto sobre Produto Industrializado (IPI) de carros durante alguns anos, abrangendo o final do segundo mandato de Lula da Silva (2007-2010) e o início do primeiro Governo Dilma Rousseff (2011-2014). Nesse caso - como em muitos outros - a função fiscal do tributo deixa de existir, passando apenas a exercer sua função extrafiscal. Além do caso citado, o mais conhecido, é prática comum - e "invisível" - de muitos governos estaduais, incluindo o cearense.

\footnotetext{
${ }^{3}$ Disponível em: www.goo.gl/Q6Aku8 Acesso em: 22 nov. 2016.

${ }^{4}$ A LRF permitiu que governos pudessem utilizar as reduções e isenções como forma de regular a economia.
} 
A prática de extrafiscalidade no Brasil tem relação íntima com o capital nacional, beneficiando produtos locais em detrimento de mercadorias estrangeiras ${ }^{5}$. (FOLLONI, 2014; LUKIC, 2015) Segundo Lukic (2015, p. 198-99), "tais medidas extrafiscais representam uma tentativa de estímulo à economia e à produção nacional e têm por fim adaptar o sistema aos novos princípios de desenvolvimento e de competitividade do país". Apesar disso, se deve destacar que a complexidade da economia global na atualidade impede que se afirme com clareza o quanto da chamada "economia nacional" é exclusivamente nacional (SASSEN, 2016). Empregos podem ser criados no Brasil, mas os lucros extraídos não necessariamente são nacionais, por exemplo.

Feita a ressalva, destaca-se que a prática da extrafiscalidade se assemelha às políticas desenvolvimentistas adotadas durante parte do século XX no país. O desenvolvimentismo visava à expansão do setor industrial nacional por meio da intervenção estatal, visto que o Estado poderia planejar de forma mais racional esse desenvolvimento do que o mercado, que é enxergado como irracional devido à sua ânsia por lucro. Ou seja: deixar essa tarefa com o mercado, oferecendo liberdade econômica, pode acarretar fracasso. Dessa forma, o Estado investiria em setores estratégicos visando ao crescimento econômico e, ainda, regularia a distribuição de riquezas, a fim de garantir o desenvolvimento social e o fomento ao mercado interno.

Tal objetivo, contudo, vem acompanhado de outras práticas que divergem do desenvolvimentismo, tais como: ações identificadas com as políticas neoliberais que visam à retirada de direitos sociais. Essas ações passaram a ser implementadas no Brasil a partir de 1990, quando o Estado passou por uma profunda reformulação a fim de minimizar sua interferência no campo econômico (VIZENTINI, 2003; LUKIC, 2015). Isto significa uma mescla das políticas desenvolvimentista e neoliberal.

Nesse sentido, a atuação do governo do estado do Ceará se aproxima das políticas neodesenvolvimentistas, isto é, o "desenvolvimentismo da época do capitalismo neoliberal" (BOITO JR.; BERRINGER, 2013, p. 32). A prática da renúncia de receitas fez com que, em 2016, o governo do Ceará abrisse mão de cerca de R $\$ 1$ bilhão e 47 milhões, conforme consta na LOA daquele ano. Isso representa 4,3\% dos $\mathrm{R} \$ 24,3$ bilhões previstos para arrecadação. A justificativa oficial do governo para isso foi a "atração de investimentos" da iniciativa privada e o "crescimento do PIB" .

\footnotetext{
${ }_{5}^{5}$ Recentemente, a Organização Mundial do Comércio (OMC) condenou essa política brasileira exatamente por interferir na concorrência internacional. Cabe recurso. Disponível em: http://www1.folha.uol.com.br/mercado/2016/11/1831528-omc-considera-ilegais-programas-da-politica-industrialbrasileira-diz-jornal.shtml Acesso em: 23 nov. 2016.

${ }^{6}$ Produto Interno Bruto, a soma de todas as riquezas produzidas no intervalo de um ano que são comercializadas no mercado formal. É importante ressaltar que o mercado informal não é medido por aquele índice.
} 
Essa prática de renúncia fiscal é também uma estratégia de estados menos desenvolvidos para tentar crescer economicamente, conforme destaca Pinto (2012, p. 32. Grifos do autor):

A política nacional de desconcentração da economia vem sendo reforçada pelas campanhas de atração de empresas, promovidas pelos governos dos estados menos desenvolvidos. O principal instrumento utilizado tem sido a renúncia fiscal temporária (isenção de impostos durante determinado período), o que vem a configurar, em certos casos, uma verdadeira "guerra fiscal" entre estados.

Vale ressaltar que a Renúncia fiscal se soma a outra prática comum de empresários cearenses - e brasileiros em geral: a evasão fiscal. Estima-se em $\mathrm{R} \$ 500$ bilhões o valor de impostos sonegados no Brasil, anualmente 7 . Segundo Pinto (2012), que colheu as opiniões de empresários da indústria e do comércio do Ceará e de Santa Catarina, "os fatores de caráter mais pragmático e estratégico (Estratégia competitiva e Estratégia de custo/benefício) são os mais significativos na explicação da propensão pela Evasão Fiscal", ou seja, os empresários sonegam impostos, segundo eles próprios, para tornarem suas empresas mais competitivas no mercado e também para ganharem mais lucro ante à (im)possibilidade de punição do Estado.

Uma última prática que será destaca tem relação novamente com a ação governamental: na "guerra fiscal" pela instalação de empresas privadas no estado, o governo cearense lançou mão do Fundo de Desenvolvimento Industrial (FDI), em que o Estado paga para uma indústria se instalar dentro de suas divisas ${ }^{8}$. Esse "pagamento", na verdade, se dá como uma forma de "devolução" do ICMS pago pela empresa, o que o diferencia das reduções e das isenções anteriormente destacadas. Entre 2010 e 2014, o governo do Ceará pagou a indústrias as seguintes quantias:

\footnotetext{
7 Valor referente a 2014. Disponível em: https://www.cartacapital.com.br/economia/sonegacao-de-impostos-e-setevezes-maior-que-a-corrupcao-9109.html Acesso em: 21 maio 2017. Importa destacar ainda que a sonegação ocorre principalmente entre as classes médias e as proprietárias, que pagam impostos "declaratórios", isto é, elas devem se declarar devedoras de tributos, abrindo margem para informações falsas (PINTO, 2012). Já os pobres, além de não atingirem o piso para declaração de Imposto de Renda, ainda necessitam gastar praticamente tudo o que ganham em mercadorias para sua sobrevivência, logo, pagam imposto embutido.

${ }^{8}$ A Lei No 10.367/1979, que cria o FDI, e suas alterações, em seu Art. 1ª diz o seguinte sobre o objetivo do Fundo: "promover o desenvolvimento das atividades industriais em todo Território do Estado do Ceará".
} 
ATUAÇÃO GOVERNAMENTAL, CRESCIMENTO ECONÔMICO E PROTEÇÃO SOCIAL:

ANÁLISE DO ESTADO DO CEARÁ (2000 - 2015)

Marcio Kleber Morais Pessoa

João Bosco Feitosa dos Santos

Tabela 1 - Valores referentes ao Fundo de Desenvolvimento Industrial do estado do Ceará entre 2000 e 2014.

\begin{tabular}{|c|c|}
\hline Anos & Valores (R\$ milhões) \\
\hline 2000 & 278,9 \\
\hline 2001 & 302,7 \\
\hline 2002 & 370,1 \\
\hline 2003 & 226,6 \\
\hline 2004 & 65,5 \\
\hline 2005 & 75,2 \\
\hline 2006 & 96,1 \\
\hline 2007 & 39,9 \\
\hline 2008 & 85,1 \\
\hline 2009 & 71,9 \\
\hline 2010 & 67,2 \\
\hline 2011 & 72,9 \\
\hline 2012 & 63,9 \\
\hline 2013 & 74,6 \\
\hline 2014 & 259,8 \\
\hline Média & 143 \\
\hline
\end{tabular}

Fonte: Diário Oficial do Estado do Ceará de 2001 a 2015.

Como se pode perceber, o governo do estado do Ceará distribuiu em média $\mathrm{R} \$ 143$ milhões para empresas cearenses no período analisado, valor bastante significativo. Vale chamar a atenção para o ano de 2014, quando o valor mais que triplicou em relação aos anos anteriores da gestão 
Cid Gomes (2007-14). Dito isso, destaca-se que o objetivo deste texto tem relação apenas com as ações governamentais (renúncia de receita e fundo de desenvolvimento), conforme ficou claro na exposição realizada na seção introdutória. Desse modo, não será analisada a evasão fiscal, visto se tratar de um crime de empresários que, muitas vezes, conta com a omissão dos governantes para ocorrer, pois é de conhecimento notório as práticas de evasão fiscal e os significativos montantes que deixam de ser arrecadados ano após ano.

\section{Extrafiscalidade, crescimento econômico e (des)igualdade social}

No período analisado neste artigo, a renúncia de receita praticada pelo governo do estado do Ceará incidiu apenas sobre o ICMS. Isso tem um impacto singular, visto que o ICMS é o principal imposto arrecadador do governo, representando mais de 50\% de sua Receita Corrente Líquida (RCL) ${ }^{9}$. Esse dado é importante porque com a diminuição da RCL, há a consequente diminuição do fundo para pagamento de pessoal, por exemplo, já que a Lei de Responsabilidade Fiscal impõe limites aos orçamentos estaduais e municipais se baseando exatamente naquela receita $^{10}$, ou seja, é por meio da RCL que o governo cumpre com suas obrigações pecuniárias junto aos servidores públicos.

Em 2016, por exemplo, o governo do estado não concedeu reajuste a nenhuma categoria de servidores públicos ${ }^{11}$ exatamente por estar próximo ao Limite Prudencial estabelecido pela $\mathrm{LRF}^{12}$. Contudo, esse limite pode ser manipulado artificialmente. A renúncia de receita implementada pelo governo cearense é uma forma de mudar isso.

\footnotetext{
${ }_{9}^{9}$ Outras fontes são: Imposto de Renda de Pessoa Física e Fundo de Participação dos Estados.

${ }^{10}$ Cf. Art. 19 da LRF.

11 Algumas categorias receberam reajuste apenas em gratificações e bem abaixo da inflação.

${ }^{12}$ O gasto com pessoal não deve exceder os $60 \%$ da Receita Corrente Líquida, segundo a LRF. O Limite Prudencial é a marca de $57 \%$, ou seja, dezenove vigésimos do limite de $60 \%$.
} 
Tabela 02 - Receita Corrente Líquida do governo do estado do Ceará 2016 com e sem renúncia de receita

\begin{tabular}{|c|c|}
\hline $\begin{array}{c}\text { RCL 2016 com renúncia de receita } \\
\text { (em R\$ milhões) }\end{array}$ & $\begin{array}{c}\text { RCL 2016 mais o valor da renúncia de } \\
\text { receita (em R\$ milhões) }\end{array}$ \\
\hline $\mathrm{R} \$ 16.506$ & $\mathrm{R} \$ 17.553$ \\
\hline
\end{tabular}

Fonte: LOA 2016

Como o Limite Prudencial ${ }^{14}$ estabelecido pela LRF é de 57\% da Receita Corrente Líquida, esse limite poderia ser diferente, caso o governo não abrisse mão de mais de $\mathrm{R} \$ 1$ bilhão. Com isso, o Limite Prudencial do orçamento do governo do Ceará em 2016 foi de aproximadamente R \$ 9,4 bilhões. Caso o governo não tivesse lançado mão da renúncia de receita, esse limite aumentaria para cerca de $\mathrm{R} \$ 10$ bilhões; incremento de $\mathrm{R} \$ 600$ milhões. Dessa forma, a renúncia de receita contribuiu para impedir o reajuste salarial e de benefícios para cerca de 165 mil servidores (ativos e inativos) e pensionistas do estado ${ }^{15}$. Como se pode perceber, a política de isenção fiscal impactou negativamente para 165 mil trabalhadores e suas famílias, cerca de meio milhão de pessoas.

Todavia, a análise dos dados selecionados indica um quadro bastante complexo da realidade cearense. Inicialmente, destaca-se que o Produto Interno Bruto cearense vem de fato crescendo nos anos analisados, a saber:

Tabela 03 - PIB cearense em anos de referência

\begin{tabular}{|c|c|c|c|c|c|}
\hline Ano & 2001 & 2006 & 2011 & $\mathbf{2 0 1 5}$ & $\mathbf{2 0 1 9}^{\mathbf{1 6}}$ \\
\hline PIB & 21.581 & 46.303 & 87.982 & 129.056 & 169.564 \\
(em R\$ milhão) & & & & & \\
\hline
\end{tabular}

Fonte: Lei Orçamentária Anual 2001 (Síntese), 2006 e 2014. Anuário Estatístico do Ceará 2013, Lei de Diretrizes

Orçamentárias 2017 (Anexo II - Anexo de metas fiscais)

\footnotetext{
${ }^{13}$ Essa é a soma simples dos dados. Não há qualquer previsão econômica constante no resultado.

14 Ao atingir o limite prudencial, o governo fica impossibilitado de: conceder reajuste salarial, criar cargos, alterar estrutura de carreiras que implique em aumento de despesa, contratação de pessoal e contratação de horas extras. $C f$. Art. 22 da LRF.

15 Dados de 2014. Fonte: Anuário Estatístico do Ceará 2015.

16 Previsão ante uma renúncia fiscal de $\mathrm{R} \$ 1,2$ bilhão.
} 
Em quinze anos, entre 2001 e 2015, houve um espantoso aumento de 600\% no PIB estadual $^{17}$; saltando para quase $800 \%$, se for considerada a previsão para 2019. Esses dados apontam para o sucesso parcial da política de renúncia fiscal do governo cearense, visto que um de seus objetivos é o "crescimento do PIB".

Ademais, o número de empresas industriais ativas também teve um crescimento extraordinário: passando de 11.238 (onze mil duzentas e trinta e oito) para 35.573 (trinta e cinco mil quinhentas e setenta e três) entre 2001 e 2014, um aumento de 316\%. No mesmo período, o número de estabelecimentos comerciais saltou de 83.092 (oitenta e três mil e noventa e dois) para 154.770 (cento e cinquenta e quatro mil e setecentos e setenta), $86 \%$ a mais. Com isso, o segundo objetivo da política de renúncia fiscal parece ter sido alcançado: "atração de investimento" da iniciativa privada.

Tabela 04 - Crescimento de empresas industriais e estabelecimentos comerciais no Ceará entre 2001 e 2014.

\begin{tabular}{|c|c|c|c|}
\hline & 2001 & 2014 & Crescimento relativo \\
\hline Empresas industriais & 11.238 & 35.573 & $316 \%$ \\
\hline Estabelecimentos comerciais & 83.092 & 154.770 & $86 \%$ \\
\hline
\end{tabular}

Fonte: Anuário Estatístico do Ceará 2002/2003 e 2015.

Mas o que isso significa para a população? Como o crescimento do PIB e os investimentos privados afetam a vida dos cearenses? Descobrir isso é bem mais complexo. Já foi exposta a situação negativa dos funcionários públicos em $2016^{18}$. Contudo, a seguir, serão feitas análises que visam à compreensão da repercussão dessas políticas na vida dos indivíduos.

Inicialmente, destaca-se a minimização do Estado na sociedade. O crescimento espantoso do PIB somado com a ausência de novas taxações mais a renúncia fiscal fizeram com que a arrecadação do Estado diminuísse proporcionalmente ao montante de riquezas produzidas, a saber:

\footnotetext{
${ }^{17}$ No mesmo período, o PIB nacional cresceu cerca de 448\%, o que indica que o crescimento econômico cearense foi bem acima da média brasileira.

18 A LOA 2017 não previu, novamente, reajuste aos servidores estaduais.
} 
Tabela 05 - Relação entre o PIB do Ceará e as Receitas totais do governo 2001, 2006, 2011 e 2015

\begin{tabular}{|c|c|c|c|c|}
\hline & $\mathbf{2 0 0 1}$ & $\mathbf{2 0 0 6}$ & $\mathbf{2 0 1 1}$ & $\mathbf{2 0 1 5}$ \\
\hline PIB (em R\$ milhão) & 21.581 & 46.303 & 87.982 & 129.056 \\
\hline $\begin{array}{c}\text { Receitas totais do governo } \\
\text { (em R\$ milhão) }\end{array}$ & 5.149 & 9.229 & 16.943 & 23.605 \\
\hline $\begin{array}{c}\text { Relação PIB / Receitas } \\
\text { totais }\end{array}$ & 23,8 & 19,9 & 19,2 & 18,3 \\
\hline
\end{tabular}

Fonte: Lei Orçamentário Anual 2001 (Síntese), 2006, 2014 e 2015. Anuário Estatístico do Ceará 2013. Lei de Diretrizes Orçamentárias 2017 (Anexo II - Anexo de metas fiscais)

Como se pode perceber, o PIB estadual vem crescendo numa proporção maior do que as receitas do governo, que caiu de $23,8 \%$ para $18,3 \%$, o que significa retração do Estado em relação aos entes privados. Todavia, isso não necessariamente significa algo negativo: haver mais dinheiro circulando entre os entes privados pode significar maior distribuição de renda, o que será analisado adiante. Em contrapartida, uma maior receita do governo pode significar a garantia de mais e melhores direitos básicos para a população com a oferta de um Estado de Bem-Estar Social ou pelo menos uma aproximação disso. Dessa forma, será discutido a seguir a (des)concentração de renda e a oferta de direitos básicos (saúde e educação) em relação à população cearense.

Primeiramente, ao se analisar a tabela a seguir, o número de pessoas ocupadas no Ceará entre 2001 e 2015 cresceu. Foi um crescimento de 9,5\%, cerca de 316 mil postos de trabalho a mais. Entretanto, ao relacionar esse dado com o crescimento de Pessoas em Idade Ativa (PIA), há um decréscimo na quantidade relativa de pessoas ocupadas, a saber: em 2001, 56\% da PIA estava ocupada. Em 2015, apenas 52,3\% estava na mesma condição ${ }^{19}$. Isto significa que, apesar das políticas de fomento econômico implementadas pelo governo cearense, o número de ocupações não acompanhou o ritma da demanda de empregos no estado, aumentando o número relativo e absoluto de pessoas não ocupadas no período analisado. Isso diverge do espantoso crescimento das bases industrial e comercial apresentados, refletidos no PIB estadual.

${ }^{19}$ Fonte: Anuário Estatístico do Ceará 2002/2003 e 2016. 
Tabela 06 - Relação entre Pessoas em idade Ativa (PIA) e população ocupada no Ceará nos anos de 2001 e 2015.

\begin{tabular}{|c|c|c|}
\hline & 2001 & $\begin{array}{c}2015 \\
\text { (aumento absoluto) }\end{array}$ \\
\hline $\begin{array}{l}\text { Pessoas em Idade Ativa } \\
\text { (em milhares de pessoas) }\end{array}$ & 5.935 & $\begin{array}{c}6.959 \\
(+1.024)\end{array}$ \\
\hline $\begin{array}{c}\text { População ocupada } \\
\text { (em milhares de pessoas) }\end{array}$ & 3.325 & $\begin{array}{c}3.641 \\
(+316)\end{array}$ \\
\hline Pessoas ocupadas/ PIA & $56 \%$ & $52,3 \%$ \\
\hline
\end{tabular}

Fonte: Anuário Estatístico do Ceará 2002/2003 e 2016.

Ademais, há outra relação importante a ser apresentada: o PIB do estado cresceu significativamente, conforme exposto. Como isso impactou nos salários dos trabalhadores? O que se quer saber é: como se comportou a renda no estado do Ceará? Segundo Piketty (2014, p. 24), “a renda consiste em dois componentes: os rendimentos derivados do trabalho [...] e a renda do capital [...]", isto é, simplificando, a renda é a soma dos salários dos trabalhadores e dos lucros dos capitalistas.

Gráfico 01 - Evolução do rendimento médio mensal de Pessoas em Idade Ativa no Ceará entre 2001 e $2015^{20}$.

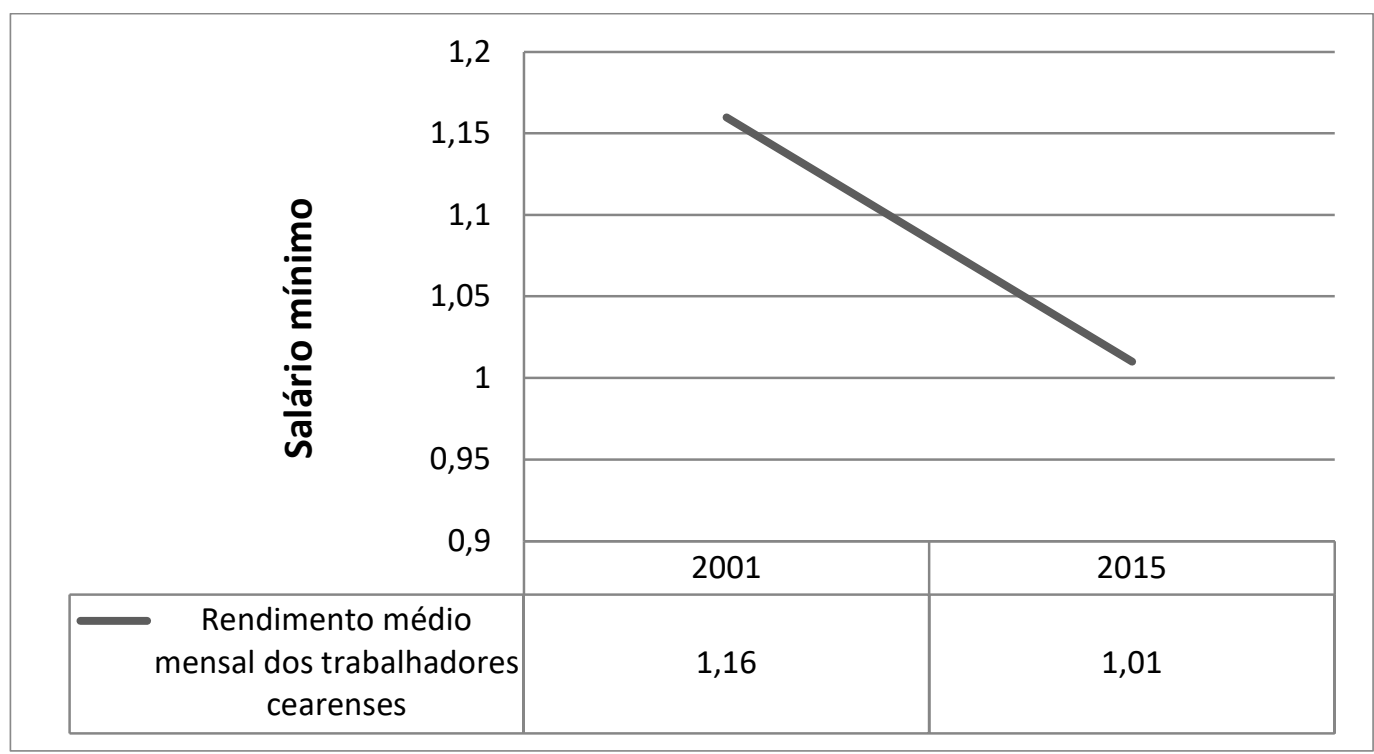

Fonte: Anuário Estatístico do Ceará 2002/2003 e 2016.

\footnotetext{
${ }^{20}$ Dados relativos às Pessoas Economicamente Ativas acompanham a tendência de queda acentuada.
} 
Neste sentido, entre 2001 e 2015, conforme pode ser observado no Gráfico 01, o rendimento médio mensal dos trabalhadores cearenses caiu de 1,16 para 1,01 salário mínimo. Vale ressaltar que $100 \%$ das ocupações criadas entre 2001 e 2015, aqueles 316 mil postos apresentados anteriormente, estão classificadas com renda entre $1 / 2$ e 2 salários mínimos, empregos de baixa remuneração, que cresceram em cerca de 515 mil postos no período analisado ${ }^{21}$.

Tabela 07 - Comparação entre o rendimento mensal de pessoas ocupadas no Ceará nos anos de 2001 e $2015 .{ }^{22}$

\begin{tabular}{|c|c|c|c|}
\hline $\begin{array}{c}\text { Relação entre anos } \\
\text { de referência } \rightarrow\end{array}$ & $\begin{array}{c}2001 \\
\text { (em milhares }\end{array}$ & $\begin{array}{c}2015 \\
\text { (em milhares }\end{array}$ & $\begin{array}{c}\text { Relação entre } \\
\text { números }\end{array}$ \\
\hline $\begin{array}{c}\text { Rendimento } \\
\text { mensal (em salário } \\
\text { mínimo) } \downarrow\end{array}$ & $\begin{array}{l}\text { de pessoas / } \\
\text { proporção) }\end{array}$ & $\begin{array}{l}\text { de pessoas / } \\
\text { proporção) }\end{array}$ & $\begin{array}{c}\text { absolutos } \\
2015 / 2001(\%)\end{array}$ \\
\hline Até $1 / 2$ & $699 / 21,3 \%$ & $559 / 15,6 \%$ & $-20,1$ \\
\hline De $1 / 2$ a 1 & $802 / 24,4 \%$ & $1.117 / 31,2 \%$ & $+39,2$ \\
\hline De 1 a 2 & $649 / 19,7 \%$ & $989 / 27,6 \%$ & $+52,4$ \\
\hline De 2 a 3 & $197 / 6 \%$ & $204 / 5,7 \%$ & $+3,5$ \\
\hline De 3 a 5 & $152 / 4,6 \%$ & $164 / 4,6 \%$ & $+7,9$ \\
\hline De 5 a 10 & $97 / 2,9 \%$ & $91 / 2,5 \%$ & $-6,2$ \\
\hline De 10 a 20 & $50 / 1,5 \%$ & $31 / 0,9 \%$ & -38 \\
\hline Mais de 20 & $19 / 0,6 \%$ & $6 / 0,2 \%$ & $-68,4$ \\
\hline Sem rendimento & $621 / 18,9 \%$ & $423 / 11,8 \%$ & $-31,9$ \\
\hline
\end{tabular}

Fonte: Anuário Estatístico do Ceará 2002/2003 e 2016.

Como se pode perceber, apesar da redução no contingente de pessoas que recebiam até meio salário e daquelas sem rendimento, houve incremento significativo apenas nas faixas salariais entre meio e dois salários. Isso contribui para explicar porque, em 2001, os salários dos trabalhadores representavam 68,9\% do PIB estadual, enquanto, em 2015, representavam apenas

\footnotetext{
${ }^{21} \mathrm{Ou}$ seja: houve uma redução geral dos salários no estado, visto que ocupações que, em 2001, pagavam mais de dois salários, em 2015, pagavam até dois salários.

22 A tabela suprime o quantitativo de pessoas ocupadas que não declararam de rendimento. Nessa categoria há 34.282 pessoas, em 2001, e 57.988, em 2015. Esses valores não foram considerados para o cálculo da proporção de cada categoria em relação ao total de pessoas ocupadas em cada ano de referência.
} 
$51,3 \%{ }^{23}$. Houve significativa redução dos rendimentos derivados do trabalho em um período de 15 anos, o que indica maior concentração de riqueza entre as classes que vivem da renda do capital, dos lucros.

Gráfico 02 - Evolução dos rendimentos de capital e de trabalho no Ceará entre 2001 e 2015.

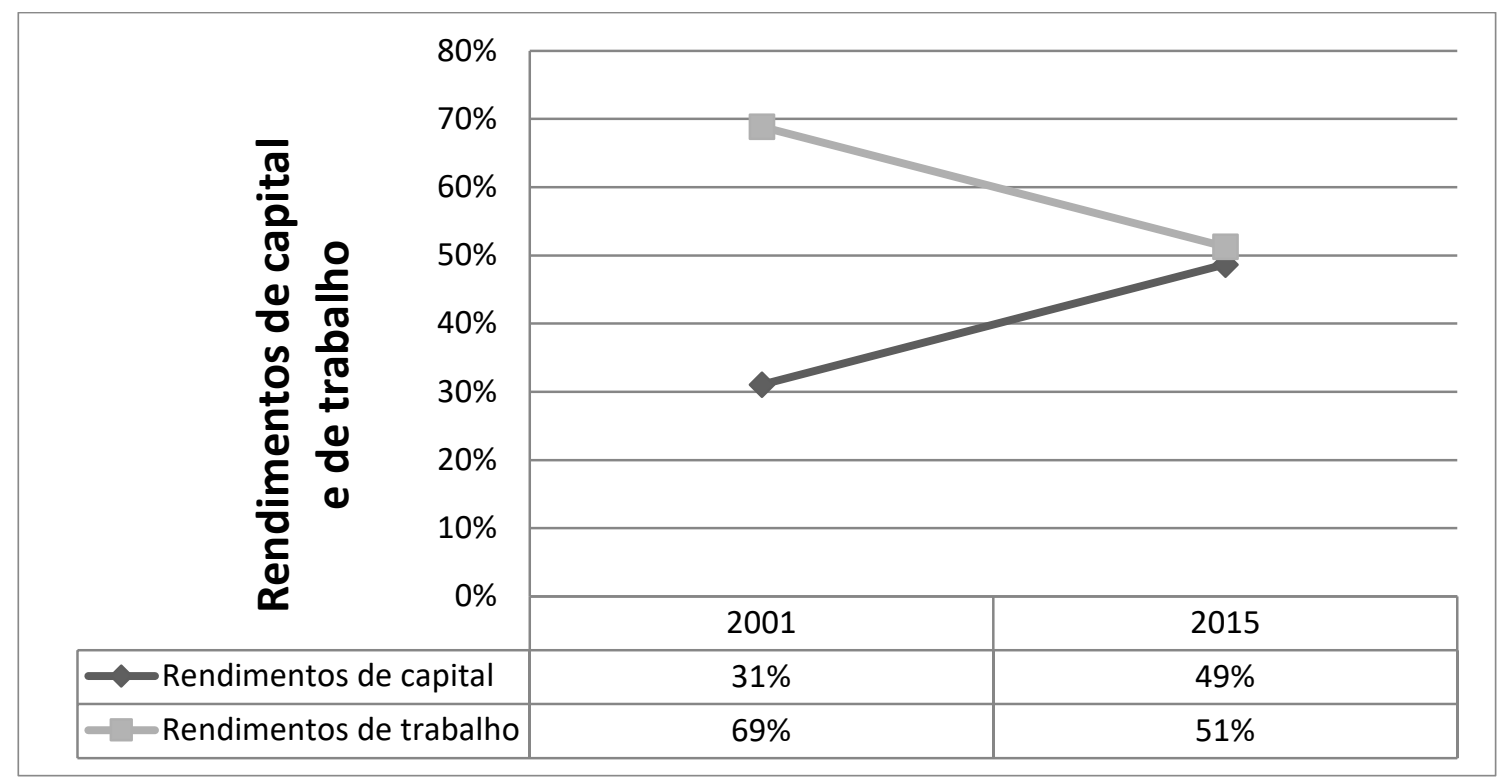

Fonte: Anuário Estatístico do Ceará 2002/2003 e 2016.

Em parte, isso ocorre porque a isenção fiscal não significou a queda de preços ao consumidor; pelo contrário, a inflação medida pelo IBGE na Região Metropolitana de Fortaleza (RMF) está entre as mais altas do país nos últimos anos. Entre 2001 e 2011, por exemplo, a inflação acumulada na RMF é maior do que a média do Brasil2 ${ }^{24}$. Isso significa que o fato constatado anteriormente - de que há mais dinheiro com entes privados - não se traduziu em maior distribuição de renda, e, sim, em concentração, pois as isenções/ reduções não foram repassadas aos consumidores nem foram transformadas em novos empregos de forma proporcional, nem em maior rendimento para os trabalhadores, tornando-se, principalmente, lucro.

\footnotetext{
23 Base do cálculo: rendimento médio mensal de Pessoa em Idade Ativa multiplicado por doze. O resultado multiplicado pelo número total de Pessoa em Idade Ativa. Fonte: Anuário Estatístico do Ceará 2002/2003 e 2016. ${ }^{24}$ Fonte: Instituto Brasileiro de Geografia e estatística (IBGE).
} 
Nesse sentido, entre 2001 e 2015, a taxa de renda do capital cresceu mais do que a taxa de crescimento econômico: $\quad 838 \%$ e $\quad 498 \%$, respectivamente. Isso é o que Piketty (2014, p. 31 et seq.) chama de "desigualdade fundamental". Quando isso ocorre constantemente, "há um risco alto de divergência na distribuição de renda" (Ibidem, p. 32), ou seja, há grande probabilidade de concentração de riqueza. Isso influi diretamente na importância da herança, desequilibrando a sociedade por longo período de tempo, caso não sejam tomadas medidas. Piketty compreende que, em geral, os países estão voltando
Gráfico 03 - Evolução dos rendimentos de capital e do PIB cearenses entre 2001 e 2015

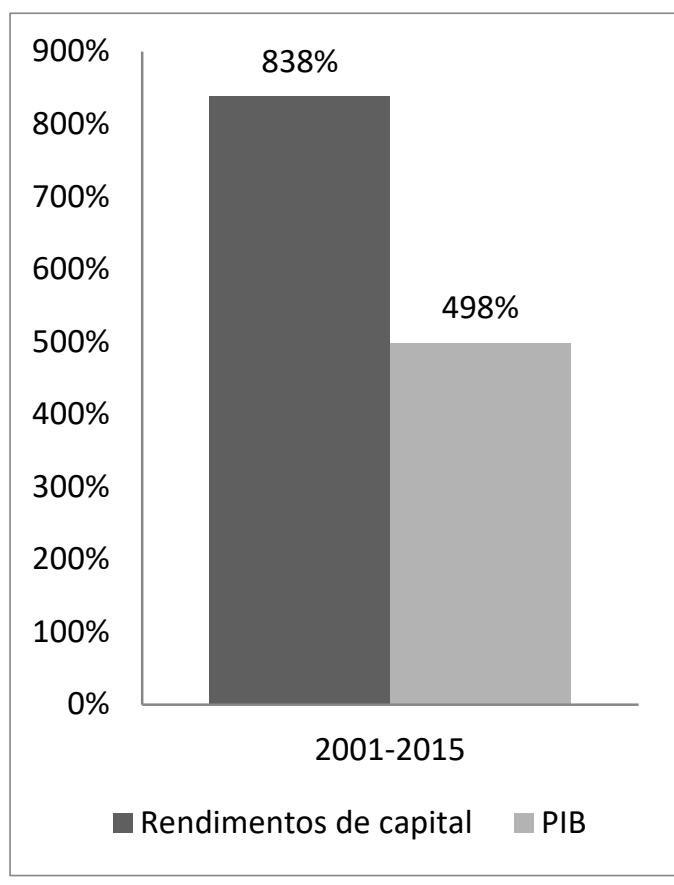

Fonte: Anuário Estatístico do Ceará 2002/2003 e 2016.

a

se tornar desiguais assim como ocorreu no final do século XIX e início do século XX, quando a desigualdade chegou a níveis jamais vistos pela humanidade. Obviamente, que o autor se refere principalmente aos países centrais do capitalismo, visto que, no Brasil, a desigualdade econômica sempre foi uma "lei de ferro".

A desigualdade naqueles países só começou a decair quando os Estados nacionais passaram a intervir diretamente na sociedade, ofertando os chamados direitos de cidadania. Esses direitos só puderam ser ofertados graças à expansão dos tributos e, consequentemente, dos fundos públicos:

De posse de maiores somas de recursos orçamentários, coube aos fundos públicos sustentar a expansão dos gastos nas áreas sociais como educação, saúde, transporte, habitação, assistência e previdência. Dessa forma foi possível garantir praticamente à totalidade da população trabalhadora uma elevação considerável do padrão de vida, assistida pela universalização de equipamentos e serviços públicos como educação e saúde (POCHMANN, 2015, p. 30) 
O autor trata especificamente dos países onde existiu Estado de Bem-Estar. Nesse sentido, uma forma de diminuir desigualdades é por meio da oferta de direitos básicos a todos os cidadãos, políticas de equidade ${ }^{25}$.

No Brasil, a redistribuição não funciona com a mesma lógica de países ocidentais. Em 2004, os $10 \%$ mais ricos do país absorviam $75 \%$ da riqueza contabilizada. Ademais, nunca houve por aqui um Estado de Bem-estar como o concebido naqueles países no pós-guerra. O pouco conquistado pelas classes subalternas não adveio de movimentos revolucionários como os experimentados por aqueles países, adveio de manifestações reivindicatórias principalmente ligadas a sindicatos pré-regulação varguista, mas sempre massacradas pelas forças conservadoras. (POCHMANN, 2015) Vale ressaltar também a importante atuação do Governo Vargas em relação aos direitos sociais, que, apesar de terem sido em geral outorgados em seu governo ditatorial, traduziram as manifestações recorrentes desde o início do século passado. Todavia, conforme destaca José Murilo de Carvalho (2016), a atuação em política social daquele governo excluiu vários trabalhadores, tais como: autônomos, domésticos e rurais" concepção da política social como privilégio e não como direito. Se fosse concebida como direito, deveria beneficiar a todos e da mesma maneira" (Ibidem, p. 118-9).

Pochmann (2015, p. 37) destaca ainda que "sem a difusão geral e qualitativa de um mínimo material e social, como educação, saúde, cultura, entre outros bens públicos, não seria suficiente ainda que necessária - a busca pela menor desigualdade econômica definida pela diferença nos rendimentos". Essa afirmação converge com análise apresentada por Barbosa (2012, p. 42-3): a renda média real do trabalhador industrial brasileiro cresceu entre 2003 e $2010^{27}$. Contudo, sua produtividade cresceu em ritmo mais acelerado desde o início do século até 2010. Isso significa que os mecanismos de extração de Mais-valia operavam para expandir a desigualdade no Brasil.

Esse cenário está levando à criação de gigantescas e poderosas corporações privadas. Conforme destacou Pochmann (2015, p. 52-3), ao se hierarquizar orçamentos públicos de Estadosnação e receitas privadas de corporações transnacionais, em 2013, o resultado é surpreendente: entre os 86 estratos iniciais, apenas 23 são ocupados por Estados-nação, enquanto 63 são

\footnotetext{
${ }^{25}$ Em complemento às colocações de Pochmann neste texto, Piketty (2014, p. 467) diz que "a redistribuição moderna é construída em torno de uma lógica de direitos e um princípio de igualdade de acesso a certo número de bens julgados fundamentais".

${ }^{26}$ Esses trabalhadores foram aos poucos sendo incluídos no rol dos direitos sociais. (CARVALHO, 2016)

${ }^{27}$ Entre 2004 e 2010, "nove em cada dez postos de trabalho criados no setor formal têm remuneração inferior a três salários mínimos" (BARBOSA, 2012). Como se viu acima, no Ceará, 100\% dos postos de empregos formais criados no período analisado se incluem na faixa salarial de até dois salários mínimos.
} 
corporações privadas. O $11^{\circ}$ estrato já é ocupado por uma corporação. Ainda segundo Pochmann (2015, p. 54-5),

\begin{abstract}
o poder privado da corporação transnacional não impacta somente no padrão monopolizado de competição intercapitalista mundial, como atua nos orçamentos públicos [...] O estado nacional sofre, assim, influências crescentes do poder privado, favorecendo o redirecionamento de parte significativa das políticas públicas a seu favor[, e conclui:] Dessa forma, o comprometimento dos orçamentos públicos com grandes corporações transnacionais esvazia políticas de apoio ao desenvolvimento, bem como o enfrentamento da desigualdade inter e intra Estados nacionais.
\end{abstract}

Essa influência perniciosa parece ser o caso da política de renúncia de receita e de desenvolvimento industrial do estado do Ceará aqui analisadas. Vale relembrar que o Brasil deu preferência às empresas nacionais. Todavia, no contexto da complexidade global atual com corporações formadas por Sociedade Anônima (SA), grandes fluxos de dinheiro saindo e entrando de fronteiras nacionais a cada instante devido às novas tecnologias etc., é difícil afirmar com exatidão o que é nacional e o que não o é. Dito isso, serão analisados a seguir dados acerca da aplicação de recursos públicos em políticas sociais no Ceará.

\title{
(Des)Igualdade social no Ceará: do crescimento econômico à (des)proteção social
}

Neste tópico, será analisada a aplicação de recursos por parte do governo estadual do Ceará em saúde e educação, duas das principais políticas sociais ofertadas pelos estados modernos, a fim de se refletir sobre a dinâmica na oferta desses direitos aos cearenses nos últimos anos. Essas análises serão permeadas por diálogos com Sassen e Wacquant. Primeiramente, serão analisadas as execuções orçamentárias da pasta de saúde: 
Tabela 08 - Previsão e Execução Orçamentária da Secretaria de Saúde do Estado do Ceará entre 2006 e $2015^{28}$.

\begin{tabular}{|c|c|c|c|c|c|c|c|c|c|}
\hline Ano & 2006 & 2008 & 2010 & 2011 & 2012 & 2013 & 2014 & 2015 & Total \\
\hline $\begin{array}{c}\text { Previsão }^{29} \\
\text { (R\$ } \\
\text { milhares) }\end{array}$ & 1.076 & 1.478 & 2.091 & 2.025 & 2.314 & 2.689 & 3.032 & 2.955 & 17.660 \\
\hline $\begin{array}{c}\text { Execu- } \\
\text { tado }^{30} \\
\text { (R\$ } \\
\text { milhares) }\end{array}$ & 851 & 1.019 & 1.556 & 1.667 & 1.956 & 2.262 & 2.767 & 2.722 & 14.800 \\
\hline $\begin{array}{l}\text { Porcen- } \\
\text { tagem } \\
\text { Executada }\end{array}$ & 79,1 & 69 & 74,4 & 82,3 & 84,5 & 84,1 & 91,2 & 92,1 & 83,8 \\
\hline
\end{tabular}

Fonte: Execução Orçamentária do Estado do Ceará dos anos de referência.

Como se pode perceber, em nenhum dos anos analisados o poder executivo estadual gastou 100\% do que estava previsto para a secretaria de saúde. A média dos seis anos, 83,8\%, é muito baixa se for considerada a situação precária da saúde pública estadual, que há anos vive em estado de calamidade com pacientes espalhados por corredores e sendo atendidos de forma precária nos hospitais públicos do estado ${ }^{31}$. Esse cenário de flagelo está forçando muitos cearenses a migrar para planos de saúde privados como uma forma de evitar vivenciar aquelas situações. No primeiro semestre de 2017, por exemplo, o número de adesões a planos de saúde está em queda no Brasil, mas continua crescendo no Ceará ${ }^{32}$. Isso certamente não está ocorrendo porque o rendimento dos

\footnotetext{
${ }^{28}$ Não foram encontrados dados anteriores a 2006.

${ }^{29}$ Previsão na LOA mais crédito suplementar (quando existir). Valor não corrigido pela inflação.

30 Valor empenhado. Valor não corrigido pela inflação.

31 Disponível em: http://diariodonordeste.verdesmares.com.br/cadernos/cidade/corredores-lotados-e-surtoevidenciam-cenario-de-caos-na-saude-1.1288110 Acesso em: 28 nov. 2016.

32 Disponível em: http://diariodonordeste.verdesmares.com.br/cadernos/negocios/15-4-mil-pessoas-aderem-aplano-de-saude-no-ce-1.1651801 Acesso em: 23 maio $2017 . \quad$ Disponível em: http://www.opovo.com.br/jornal/economia/2017/02/planos-de-saude-ganham-mais-de-4-mil-clientes-no-ce.html Acesso em: 23 maio 2017.
} 
trabalhadores está crescendo, conforme já discutido. Ademais, isso está transformando a noção de saúde como direito, passando a ser enxergada como mercadoria; além de ter enorme impacto sobre os orçamentos familiares já tão depreciados. Ademais, a situação da saúde se agrava e se torna mais urgente para os indivíduos com a apresentação de outro dado: em 2015, apenas 52\% dos domicílios cearenses possuíam esgotamento sanitário adequado, bem abaixo da média nacional, que passou de $80 \%$ naquele ano, segundo dados do IPECE (2016).

Outro direito social que sofreu o mesmo problema de redução de investimentos foi a educação. Novamente, em nenhum ano analisado o governo executou o previsto ${ }^{33}$ :

Tabela 09 - Previsão e Execução Orçamentária da Secretaria de Educação do Estado do Ceará entre 2006 e $2015^{34}$.

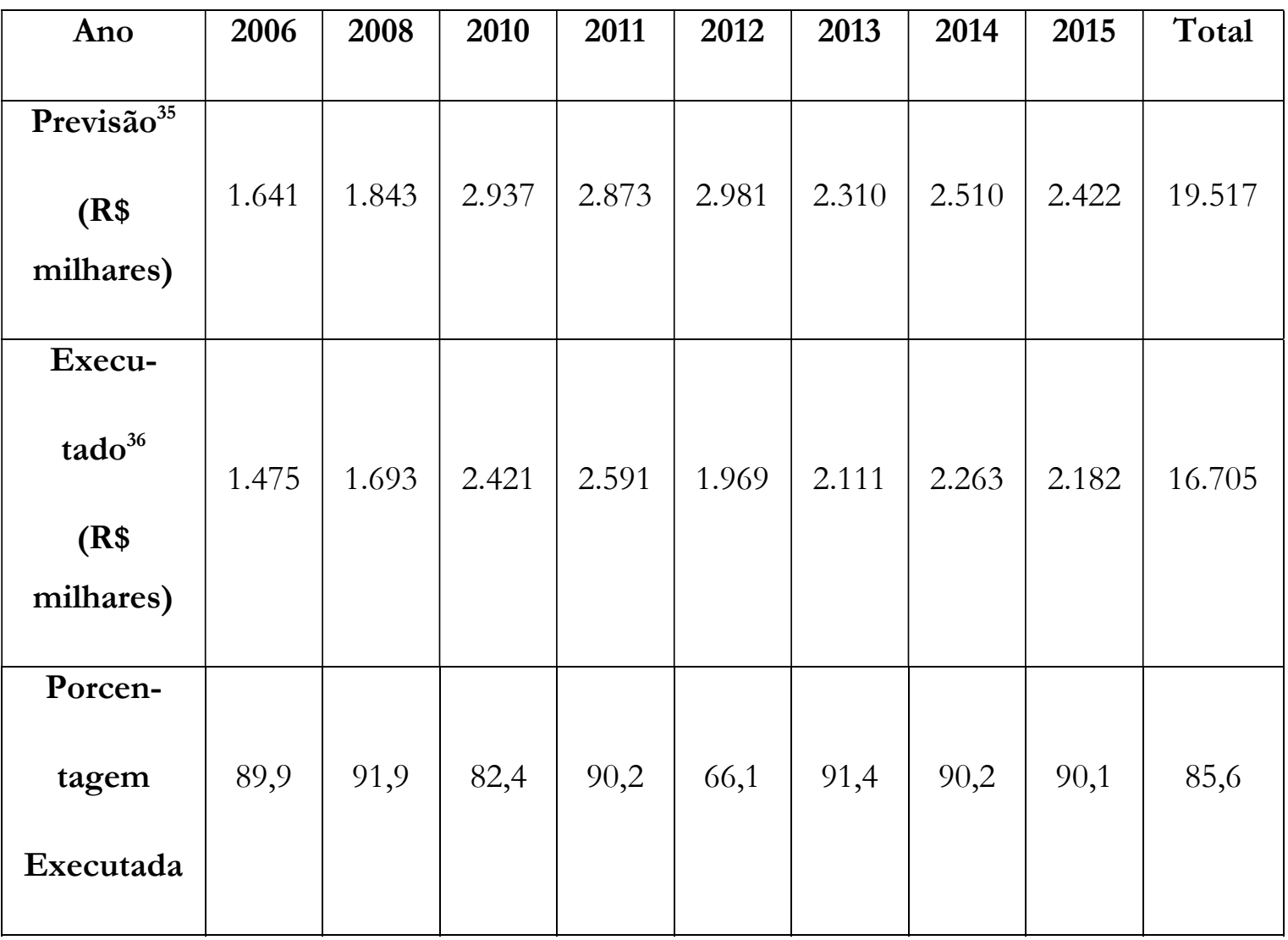

Fonte: Execução Orçamentária do Estado do Ceará dos anos de referência.

\footnotetext{
33 O gasto com educação no Ceará é dividido: uma parte dos gastos é executada pelo governo estadual e outra parte, pelo governo federal por meio do Fundo de Manutenção e Desenvolvimento da Educação Básica e de Valorização dos Profissionais da Educação (Fundeb). Isso ocorre quando os 25\% dos orçamentos estaduais que devem ser obrigatoriamente destinados à educação não atingem o "valor médio ponderado por aluno", sendo complementado por aquele Fundo.

34 Não foram encontrados dados anteriores a 2006.

35 Previsão na LOA mais crédito suplementar (quando existir). Valor não corrigido pela inflação.

36 Valor empenhado. Valor não corrigido pela inflação.
} 
Vale ressaltar que tanto no caso da educação quanto no da saúde o governo estadual gastou o percentual mínimo constitucionalmente previsto. Contudo, as execuções foram bem abaixo do inicialmente previsto e divulgado na mídia como propaganda. Em 2011, por exemplo, durante uma greve dos professores da rede estadual, o governo se utilizou da porcentagem de gasto com educação sobrevalorizada como argumento na disputa com a categoria grevista:

O Governo do Estado reafirma seu forte compromisso com a Educação pública de qualidade, demonstrado na prática também pelo aumento expressivo da parcela do Orçamento Estadual dedicada ao setor, que hoje é de 29,55\% de tudo o que o Governo arrecada com os impostos dos contribuintes. ${ }^{37}$

De fato, o governo não chegou a gastar a porcentagem divulgada, gastando cerca de $\mathrm{R} \$$ 200 milhões a menos. Um dos possíveis efeitos disso é a queda brusca no número de matrículas na rede estadual, a saber:

Tabela 10 - Matrículas na Educação Básica na rede estadual do Ceará38.

\begin{tabular}{|c|c|c|c|c|c|c|c|c|}
\hline Ano & $\mathbf{2 0 0 2}$ & $\mathbf{2 0 0 5}$ & $\mathbf{2 0 1 0}$ & $\mathbf{2 0 1 1}$ & $\mathbf{2 0 1 2}$ & $\mathbf{2 0 1 3}$ & $\mathbf{2 0 1 4}$ & $\mathbf{2 0 1 5}$ \\
\hline $\begin{array}{c}\text { Matrículas } \\
\text { absolutas (x } \\
\text { 1000) }\end{array}$ & 725 & 734 & 522 & 521 & 503 & 486 & 462 & 432 \\
\hline $\begin{array}{c}\text { Matrículas } \\
\text { relativas (\%) }\end{array}$ & 100 & 101 & 72 & 72 & 69,4 & 67 & 63,7 & 59,6 \\
\hline
\end{tabular}

Fonte: Sinopse Estatística da Educação Básica (MEC/ INEP) nos anos de referência.

Como se pode perceber, o número de matrículas vem despencando intensamente no período analisado. 293 mil matrículas foram encerradas, 40\% do total. Todavia, esse número acompanha, em parte, a evolução etária da população cearense entre 5 e 19 anos, que foi reduzida no mesmo período em 270 mil pessoas. Apesar disso, um outro dado indica a situação da educação escolar cearense com mais clareza:

\footnotetext{
${ }^{37}$ Disponível em: www.goo.gl/PCT0kn Acesso em: 30 nov. 2016.

${ }^{38}$ Incluindo todos os níveis de ensino constantes nos documentos: creche, pré-escola, classes de alfabetização, infantil, fundamental, classes de aceleração, médio, profissional e Educação de Jovens e Adultos.
} 
Tabela - População de 0 a 19 anos e matrículas em todas as esferas administrativas na educação básica no Ceará $(2002-2015)^{39}$

\begin{tabular}{|c|c|c|}
\hline Ano & População de 0 a 19 anos (x 1000) & $\begin{array}{c}\text { Matrículas em todas as esferas } \\
\text { administrativas (x 1000) }\end{array}$ \\
\hline 2002 & 3.309 & 2.950 \\
\hline 2015 & 2.784 & 1.820 \\
\hline $2015 / 2002$ & -525 & -1.130 \\
\hline
\end{tabular}

Fonte: Sinopse Estatística da Educação Básica 2002 e 2015 e Anuário Estatístico do Ceará 2016.

Como se pode perceber, a redução da população de 0 a $19 \operatorname{anos}^{40}$ - alvo principal das políticas educacionais - foi menos da metade do total de matrículas encerradas no Ceará no período analisado. Isso, somado com os dados apresentados anteriormente sobre trabalho, está impactando diretamente em outro fenômeno preocupante na sociedade cearense: o aumento do número de jovens que nem estudam e nem trabalham. No Ceará, esse número oscilou bastante entre 2005 e 2014, tendo crescimento vertiginoso de mais de $15 \%$ em 2015 . Neste ano, $27,6 \%$ dos jovens entre 15 e 29 anos estava naquela situação, segundo dados do IPECE (2016).

No mesmo sentido, e ainda com dados do IPECE (2016), a taxa de analfabetismo no Ceará entre pessoas com 15 anos ou mais, que vinha caindo desde 2005, passou a oscilar a partir de 2011, e cresceu mais de 6\% em 2015, atingindo o total de 17,3\% da população, mais que o dobro da média nacional. Também em 2015, o número de analfabetos funcionais ${ }^{41}$ cresceu no estado, passando de 26,4\% para 27,1\%. Já o número médio de anos de estudo entre os cearenses com 25 anos ou mais, que estava em ascensão desde 2005, estacionou entre 2013 e 2015 em 6,4 anos. Esses dados indicam que o cenário destacado anteriormente de queda no investimento na área educacional está afetando diretamente no perfil da população em relação aos estudos formais, com relativa piora nos dados estruturais do setor.

Como se pode perceber, o Estado vem abrindo mão de recursos nos últimos anos em favor dos empresários, principalmente industriais, por meio da Renúncia de receita e também do Fundo

\footnotetext{
${ }^{39}$ Os dados de 2001 da Sinopse Estatística da Educação Básica não estão organizados da mesma forma que os documentos dos anos seguintes.

${ }^{40}$ Importa destacar que a população cearense de 20 ou mais teve aumento no período em todas as categorias, sem exceções.

${ }^{41}$ Analfabeto funcional é qualquer pessoa com 15 anos ou mais que tenha menos de quatro anos de estudo.
} 
de Desenvolvimento Industrial (FDI). A ausência desses recursos está impactando diretamente a distribuição de renda e de direitos entre os ditos cidadãos. Isso significa que o crescimento vertiginoso do PIB cearense, isto é, o crescimento da produção de riquezas, não resultou em distribuição dessa riqueza; pelo contrário, está levando a um cenário degradante para a população do Ceará.

Importa frisar também que a responsabilidade pelo que vem ocorrendo não é exclusivamente do governo do estado do Ceará. De fato, o governo de um estado pouco desenvolvido do Nordeste brasileiro não teria muitas chances em se desvencilhar de uma rede maior e mais poderosa que se tornou a economia global. Apesar de o governo cearense estar atuando - frise-se - em favor desse modelo exploratório global, ele é apenas mais uma peça na grande engrenagem que é hoje a economia global. Conforme destacou Pinto (2012), há uma "guerra fiscal" em curso no Brasil, logo, entre os estados menos desenvolvidos, aquele que oferecer as condições mais favoráveis aos grandes empresários - e, geralmente, menos favoráveis aos seus cidadãos - provavelmente ganhará o status de estado-sede de uma grande empresa (multi)nacional. Para um governo eleito e temporário que precisa "mostrar serviço" em quatro anos para que possa pleitear sua reeleição, isso pode fazer a diferença. Não à toa, o FDI alcançou seu teto na gestão Cid Gomes em 2014, ano de eleição estadual ${ }^{42}$, conforme exposto na Tabela 01.

Faz também parte dessa rede maior o governo federal, deputados e senadores, grandes corporações capitalistas etc. Ademais, um cidadão, isoladamente, pode contribuir para essa engrenagem, visto que uma das principais características da economia global é sua complexidade, como destaca Sassen (2016). O simples fato de um trabalhador de renda baixa ou média poder guardar um pouco do que lhe sobra no final do mês em sua poupança no banco ou investir em algum plano financeiro como, por exemplo, o Tesouro Direto ${ }^{43}$, já é o suficiente para a engrenagem da complexa economia global continuar rodando, pois aquela quantia em dinheiro deixará de existir como moeda e passará a flutuar mundo afora podendo tornar-se qualquer tipo de ação que gere mais lucro, podendo servir, por exemplo, como empréstimo de um banco ou outra instituição financeira global a uma grande corporação (multi)nacional que usará seu poder e dinheiro (aquele proveniente do trabalhador do exemplo) para realizar lobby no Congresso Nacional, a fim de diluir

\footnotetext{
42 Investigações da Operação Lava-Jato indicam inclusive que o montante gasto em 2014 pela FDI tem relação com subornos do governo em troca de doações para aquela campanha eleitoral. Todavia, as investigações continuam em curso, não havendo prazo para julgamentos. Disponível em: https://oglobo.globo.com/brasil/delacoes-revelamesquema-de-propina-em-troca-de-creditos-tributarios-21404518 Acesso em: 28 maio 2017.

43 "O Tesouro Direto é um Programa do Tesouro Nacional desenvolvido em parceria com a BMF\&F Bovespa para venda de títulos públicos federais para pessoas físicas, por meio da internet. [...] esse Programa surgiu com o objetivo de democratizar o acesso aos títulos públicos, ao permitir aplicações com apenas $\mathrm{R}$ \$ 30,00”. Disponível em: http://www.tesouro.fazenda.gov.br/tesouro-direto-conheca-o-tesouro-direto Acesso em: 23 maio 2017.
} 
os direitos trabalhistas, ou expandir a terceirização, ou desregulamentar os direitos previdenciários no Brasil. Isso é o que Sassen (2016, p. 22. Grifo da autora) chama de "formações predatórias", a saber: "estamos assistindo à constituição não tanto de elites predatórias, mas de formações predatórias, uma combinação de elites e de capacidades sistêmicas na qual o mercado financeiro é um facilitador fundamental, que empurra na direção de uma concentração aguda". E continua: “essas capacidades sistêmicas são uma combinação variável de inovações técnicas, de mercado e finanças, mais a permissão governamental” (SASSEN, 2016, p. 23).

Isso acarreta o que a autora chama de "expulsões", que não têm relação somente com deslocamento espacial, como a palavra pode levar a entender, essas expulsões podem ser "de projetos de vida e de meios de sobrevivência, de um pertencimento à sociedade, e do contrato social que está no centro da democracia liberal" (SASSEN, 2016, p. 39). Certamente, no caso brasileiro e, principalmente, cearense, não se pode falar em contrato social e democracia liberal sem se utilizar aspas - ou mesmo, não se pode falar. Apesar disso, é possível analisar a situação cearense a partir da generalização do conceito destacado, visto que, ao se analisar os dados anteriores, percebe-se que as condições de vida de uma parte significativa da população cearense estão ruindo na mesma intensidade com que riquezas são geradas - e concentradas - e com que o governo abre mão de seus fundos públicos em prol de um crescimento econômico desregulamentado, gerando “expulsões" de pessoas do Sistema Único de Saúde, da escola básica, de empregos melhor remunerados etc. Isso pode ser traduzido como a tensão entre instrumentos complexos e resultados brutalmente elementares (SASSEN, 2016, p. 260). Como destaca Wacquant (2005, p. 191): "Opulência e indigência, luxo e penúria, profusão e míngua floresceram lado a lado[, desde os anos 1970]”, e conclui: “Os dois tipos de fenômenos, apesar de aparentemente contraditórios, estão na realidade ligados”, essa parece ser a contribuição das novas formações capitalistas.

No Ceará, especificamente, o nível de desigualdade social aponta para seu aumento. Além dos dados analisados neste texto, destaca-se a redução do IDH cearense entre 2000 e 2010, anos de realização do Censo pelo IBGE, passando de 0,699 para $0,682^{44}$, o que indica piora. No sentido contrário, o Índice de Gini do estado teve acentuada queda, o que indica melhora, entre 2001 e 2015, passando de 0,610 para $0,491^{45}$.

\footnotetext{
44 Índice de Desenvolvimento Humano. Fonte: Anuário Estatístico do Ceará 2013.

${ }^{45}$ Fonte: Instituto de Pesquisa e Estratégia Econômica do Ceará - IPECE. Vale ressaltar que o Índice de Gini, assim como qualquer outro índice que busque medir a desigualdade, possui suas limitações por tentar expor uma realidade multidimensional em um dado unidimensional. (Cf. PIKETTY, 2014) Ademais, geralmente o Índice de Gini compara apenas a renda média dos $20 \%$ mais ricos com a dos $20 \%$ mais pobres. Em um país extremamente desigual como o Brasil, essa metodologia não necessariamente é a mais acertada, visto que entre os $20 \%$ mais ricos constam pessoas que ganham rendimentos relativamente baixos provenientes do trabalho (juntamente com o centésimo mais rico que provavelmente vive da renda do capital), contribuindo para baixar a renda média desse grupo, gerando distorções.
} 
Dessa forma, os índices apontam sentidos inversos em relação à condição de vida da população cearense nesse início de século. Apesar disso, há crescente desproteção social nos últimos anos. Todavia, a medição da desigualdade social por meio de índices é sempre complexa porque, como diz Piketty (2014, p. 264), “o modo como se procura medir a desigualdade jamais é neutro". Isto é, os índices não mostram, por exemplo, redução dos salários médios entre 2001 e 2015 e a alta inflação da RMF, conforme apresentados anteriormente. Também não detalham a execução deficiente do orçamento estadual nas áreas de saúde e educação. No mesmo sentido, escreve Sassen (2016, p. 54) ao abordar o relativo crescimento do PIB da Grécia durante a crise econômica: "é uma medida de crescimento que existe em paralelo à crescente pobreza, ao desemprego, aos sem-teto, à fome, à distribuição de alimentos por organizações de caridade, às taxas de suicídio entre os donos de pequenos negócios falidos e muito mais". Sassen se questiona se esse "crescimento" apontado pelas medições tradicionais não é proposital, a fim de deixar esquecidas todas as mazelas sociais que os órgãos oficiais não têm interesse em mostrar, as "expulsões".

\section{Considerações finais}

A conjuntura econômica atual do Brasil está certamente transformando suas bases sociais. Os direitos sociais conquistados principalmente pela Consolidação das Leis do Trabalho de 1943 e pela promulgação da Constituição de 1988 estão em xeque nesse momento histórico devido às várias reformas que estão sendo pretendidas ou votadas aceleradamente no Congresso Nacional. No Ceará pré-impeachment, os dados aqui analisados apontam piora na proteção social dos cidadãos e consequente aumento da desigualdade social, o que se reflete nos dados macrossociais analisados.

Dito isso, serão comentados a seguir os resultados relacionados aos objetivos deste texto: pode se compreender que as políticas de renúncia de receita e de desenvolvimento industrial no Ceará têm sido negativas para a proteção social realizada pelo Estado, especificamente nas áreas de saúde e de educação. Apesar de exitosa em relação ao crescimento do PIB e à atração de investimentos privados, as isenções fiscais não conseguiram expandir o número de ocupações na mesma proporção, nem conseguiram criar postos de trabalho bem remunerados, havendo queda na renda média do trabalhador cearense (e aumento da renda proveniente do capital, dos lucros). Isso sem contar a efetivação deficiente nos orçamentos das pastas de saúde e de educação, entre 2006 e 2015. Esse conjunto de fatores levou a maior concentração de renda, havendo largo crescimento nos ganhos de capital no Ceará, entre 2001 e 2015. 
A soma da deficiente efetivação dos direitos sociais, da queda na renda dos trabalhadores e da alta inflação acumulada desenhou a conjuntura atual do estado do Ceará, acarretando “expulsões"; em parte, resultado de decisões políticas do Estado. Nesse sentido, finaliza-se este texto com uma afirmação-chave de Wacquant (Ibidem, p. 195): "Estados fazem diferença - isto é, quando assumem a tarefa de proteção". Todavia, o Estado cearense faz a diferença, mas a proteção oferecida pelo ele nem sempre é social e nem sempre é para quem de fato precisa dela.

\section{Referências}

BARBOSA, Alexandre de Freitas (Org.). O Brasil real: a desigualdade para além dos indicadores. São Paulo: Outras Expressões, 2012.

BOITO JR, A.; BERRINGER, T. Brasil: classes sociais, neodesenvolvimentismo e política externa nos governos Lula e Dilma. In: Revista de Sociologia e Política. v. 21, nº 47: 31-38 set. 2013.

BRASIL. Ministério da Educação. Sinopse Estatística da Educação Básica 2002. Brasília. 2003. Ministério da Educação. Sinopse Estatística da Educação Básica 2015. Brasília. 2016.

CARVALHO, José Murilo de. Cidadania no Brasil: o longo caminho. $21^{\mathrm{a}}$ ed. Rio de Janeiro: Civilização Brasileira, 2016.

CEARÁ. Relatório de Gestão da Secretaria de Segurança Pública e Defesa Social 2015/2016. Fortaleza, 2016.

. Instituto de Pesquisa e Estratégia Econômica do Ceará. Anuário Estatístico do Ceará 2002/2003. Fortaleza, 2004.

Instituto de Pesquisa e Estratégia Econômica do Ceará. Anuário Estatístico do Ceará 2013. Fortaleza, 2014.

Instituto de Pesquisa e Estratégia Econômica do Ceará. Anuário Estatístico do Ceará 2015. Fortaleza, 2016.

Instituto de Pesquisa e Estratégia Econômica do Ceará. Anuário Estatístico do Ceará 2016. Fortaleza, 2017.

CELLARD, André. A análise documental. In: POUPART, Jean et al. A pesquisa qualitativa: enfoques epistemológicos e metodológicos. Petrópolis-RJ: Vozes, 2014.

FOLLONI, André. Isonomia na tributação extrafiscal. In: Revista Direito GV. São Paulo, n. 10(1), p. 201-220, jan-jun 2014.

Instituto de Pesquisa e Estratégia Econômica do Ceará - IPECE. Síntese dos indicadores sociais do Ceará 2016. Pesquisa Nacional por Amostra de Domicílios - PNAD/IBGE. Dezembro de 2016. 
LUKIC, Melina de R. S. Extrafiscalidade e regulação da economia: as mudanças tributárias nos governos Lula e Dilma. In: Sequência. n. 71, p. 197-220, dez. 2015.

PIKETTY, Thomas. O Capital no século XXI. Rio de Janeiro: Intrínseca, 2014.

PINTO, Francisco Roberto. Evasão fiscal como estratégia: percepções de empresários brasileiros. Fortaleza: EdUECE, 2012.

POCHMANN, Marcio. Desigualdade econômica no Brasil. São Paulo: Ideias \& Letras, 2015.

SASSEN, Saskia. Expulsões: brutalidade e complexidade na economia global. Rio de Janeiro/ São Paulo: Paz e Terra, 2016.

VIZENTINI, Paulo G. F.. A política externa brasileira em transição: do desenvolvimentismo ao neoliberalismo. In: MARTINS, Estevão C. de R. (Org.). Relações internacionais: visões do Brasil e da América Latina. Brasília: Funag/Ibri, 2003.

WACQUANT, Loïc. Os condenados da cidade: estudos sobre marginalidade avançada. $2^{\mathrm{a}}$ ed. Rio de Janeiro: Revan; FASE, 2005. 